INTERNATIONAL JOURNAL OF MULTidisciplinARy RESEARCH AND ANALYSis

ISSN(print): 2643-9840, ISSN(online): 2643-9875

Volume 04 Issue 07 July 2021

DOI: 10.47191/ijmra/v4-i7-04, Impact Factor: 6.072

Page No.- $880-889$

\title{
Knowledge, Attitudes and Practices of Hypertension amongst Apparently Healthy Adults in a Rural Setting in Rivers State
}

\author{
Wekhe Chidinma ${ }^{1}$, Amaewhule Mary. $\mathrm{N}^{2}$, Daka lyaeneomie $\mathrm{R}^{3}$ \\ ${ }^{1}$ Department of Radiology, Rivers State University Teaching Hospital, Port Harcourt. \\ ${ }^{2}$ Department of Internal Medicine, Rivers State University Teaching Hospital, Port Harcourt. \\ ${ }^{3}$ Department of Pharmacology, Rivers State University, Port Harcourt.
}

ABSTRACT: Hypertension is a major risk factor for cardiovascular and cerebrovascular diseases. The prevalence of hypertension is increasing in our environment. The objective of this study is to assess knowledge, attitude and practice of hypertension, which is a crucial element of hypertension control but little information is available from developing countries where hypertension has lately been recognised as a major health problem. Therefore, we examined KAP on hypertension amongst apparently healthy adult population. A cross-sectional study was conducted amongst 107 adults- 80 females and 27 males between the ages of $18 y e a r s$ and 80 years for a period of 3 months using random sampling. KAP score about hypertension was deduced from a set of KAP related questions/questionnaire. Results show that $74.8 \%$ were females and $25.2 \%$ were males. About $46.7 \%$ of the respondents were self-employed followed by $17.8 \%$ unemployed and $6.5 \%$ were students. More than half (78.5\%) of the respondents had proper knowledge on hypertension. Almost all (90.7\%) had positive attitude toward. Hypertension. About $13.1 \%$ never checked their blood pressure except for when they get to the hospital for some other reasons, $13.1 \%$ also neither exercised nor consulted a health care provider. Most of the participants (51.4\%) never consumed alcohol nor smoked (91.6\%).

KEYWORDS: hypertension, adult population, knowledge, attitude, practice

\section{INTRODUCTION}

Hypertension is a worldwide public challenge because of its high frequency and related risks of cardiovascular, cerebrovascular and other end organ diseases ${ }^{1}$ It is a chronic circulatory disease, and one of the most widespread non-communicable disease globally. Hypertension is preventable but mismanagement leads to serious medical complications like heart failure, stroke, renal failure, subarachnoid haemorrhage etc ${ }^{2}$. More than 360,000 deaths in US occurred due to hypertension ${ }^{3}$.

It is a condition that occurs when there is a persistent elevation of the blood pressure: systolic greater than $140 \mathrm{mmHg}$ and diastolic greater than $90 \mathrm{mmHg}$. Diagnosis is not made with just a single measurement except it is extremely high (above 170-180mmHg) It has been identified as a prominent risk factor for mortality and is ranked third as a cause of disability ${ }^{4}$.

Hypertension can be classified into two classes: primary and secondary. Primary hypertension is more common and is known as fundamental hypertension and is seen in $95 \%$ of people while secondary hypertension is less frequent and is caused by another medical condition ${ }^{5}$.

Most people with hypertension have no symptoms at all, this is why it is called the silent killer ${ }^{5}$. In the rural area, which is where the study was carried out, most people there are not interested in visiting the physician when they are sick probably because of their poor socio-economic status as well as lack of awareness ${ }^{4}$. Consequently, there are more undetected and untreated hypertension in the rural areas. According to World Health Statistics 2017, an estimated 17.7 million deaths occurred due to cardiovascular disease, accounting for $45 \%$ of all non-communicable disease deaths ${ }^{6}$.

It is important for everyone to know their blood pressure reading, because if hypertension is detected early it will minimize the risk of heart attack, heart failure, stroke and other end organ damage that could be caused by hypertension. As with other noncommunicable diseases self-care can facilitate early detection of hypertension. Therefore, adherence to medication and healthy life styles are key to good blood pressure control. The prevalence and associated complications of hypertension are multi factorial like positive family history, presence of obesity, misdiagnosis and inappropriate or insufficient therapy. In addition, hypertension is also associated and influenced by many genetic, hormonal, metabolic, neurologic and psychological factors. 


\section{Knowledge, Attitudes and Practices of Hypertension amongst Apparently Healthy Adults in a Rural Setting in Rivers State}

Hypertension is also influenced by rapid urbanization, changes in socioeconomic conditions such as sedentary lifestyle, alcohol consumption, excessive salt intake and increased stress and these factors are likely to increase in the future ${ }^{7}$. Beside lack of healthcare information and facilities, individual attitudes and other cultural behaviours affect healthcare seeking behaviour.

The most important factors which play a role in the prevalence of hypertension are lack of knowledge, negative attitudes and malpractices which is also the situation in this case study. Therefore, KAP surveys have been widely used as public health research tools to evaluate health related $\mathrm{KAP}^{8}$. The KAP survey remains a useful tool in our environment where the level of health information and literacy remains low and unquantified ${ }^{9}$. Moreover, hypertension knowledge and practice plays a significant role in controlling high blood pressure and in preventing its long term complications and comorbidity ${ }^{10}$. Hypertension has become a significant problem in developing countries experiencing epidemiologic transition from communicable to non-communicable diseases ${ }^{11}$.The emergence of hypertension and other cardiovascular diseases as public health problems in these countries is strongly related to the ageing of the population, urbanization and socioeconomic changes favouring sedentary lifestyles, obesity, salt intake, alcohol consumption among others.

The effective use of healthcare services to control these emerging chronic diseases is particularly needed in developing countries because resources are limited and must be shared with the concurrent burden of persistent communicable diseases. In this context hypertension presents a major area of intervention because it is a frequent condition that can be controlled through nonpharmacological lifestyle modifications and pharmacological treatment.

The pharmacological treatment of hypertension has been found effective in reducing blood pressure and subsequently cardiovascular events though the blood pressure levels achieved in treated patients may still be considerably higher than those in truly normotensive patients. The lifestyle modification measures required to control hypertension include reduction of salt intake, complete abstinence from alcohol and smoking, increase in physical activity and reduction of weight as well as dietary control as regards reduction of intake cholesterol containing foods.

Non-pharmacological measures (lifestyle modifications) have brought about significant reductions of $14 \%$ in mortality caused by stroke, $9 \%$ in mortality caused by heart disease and $7 \%$ in all cause mortality ${ }^{12}$

Despite all that is known about its adverse health consequences, hypertension is still poorly controlled in nigeria ${ }^{13,14}$.

A survey conducted in Quetta Pakistan revealed that due to lack of knowledge of hypertension, $18 \%$ of the general population in Pakistan experienced ill effects of hypertension. One third of individuals over 40years of age progressively had extensive variety of illnesses including myocardial infarction, atrial fibrillation, stroke and renal failure (Saleem, Hassali, Shafie, Awad and Bashir, 2011).

In America because of high literacy rate, the people have knowledge about their health status and so there is a low prevalence of hypertension compared to developing countries like Nigeria ${ }^{15}$.

According to a report from the World Health Organization (WHO 2010), there was an estimated 972 million people with hypertension in the year 2000. 65\% lived in developing world with the number predicted to grow to 0.5 billion people by 2025 .

This could be due to the fact that the lowest treatment pharmacologically is recorded to be $7.5-12 \%$ in a developing country like Ghana and so there is an urgent need to understand the disease and measures of controlling it in order to achieve good blood pressure control.

AIMS-

1. To identify knowledge, gaps, cultural beliefs and behavioural patterns that may identify needs, problems and barriers to help plan and implement interventions.

2. To deepen the understanding of commonly known information, attitudes and factors that influence behaviour.

3. To generate baseline levels and measure changes that result from interventions.

4. To assess and identify communication processes and sources important for program implementation and effectiveness.

5. To help set program priorities and make program decisions.

\section{METHODOLOGY}

The study was a cross-sectional descriptive study, conducted in a rural area called Fimie, one of the villages in Okrika which is one of the ethnic groups in Rivers State Niger Delta region of Southern Nigeria.

The study was conducted over a period of 3months, December 2020- February 2021. The study population were made up of adults from age 18-80years. A clarified questionnaire was formulated to collect information from the selected respondents.

The population was made up of 107 adults -27 males and - 80 females. They were randomly chosen from unconventional setting like churches in a rural area. Awareness was created with the use of town criers and serial announcements in churches prior to the date of sample collection. 
A screening questionnaire, was given to participants and no monetary or any form of inducement was required of them. The questionnaire consists of 32 items and it was formulated to collect information from the selected respondents. The data was first checked, scrutinized, cleaned and entered into the computer after which the data was edited to rule out double or wrong entry. The data was analysed using the IBM SSPS 23.0 version.

A verbal consent was obtained from all participants and they were also informed that they had a right to withdraw from the study at any time without any threat or disadvantage.

This study was approved by the Ethical Review Committee of the Ministry of health Rivers State, Nigeria.

The inclusion criteria included being 18years of age and above. Pregnant women, lactating women, children and obviously sick people were excluded from the study.

Life style modification- Some form of education on life style modification was also given to the participants accordingly.

Method-- The blood pressure measurement was done with clinically validated manual sphygmomanometers. Manual sphygmomanometer, consist of a non-inflatable rubber cuff, a pump and a column of mercury or a digital read out reflecting pressure in an air column. Values were obtained after resting for $5 \mathrm{mins}$ in a seated position, with 30seconds interval between cuff inflation.

An average of 3 measurements were be taken, and care was also taken to select the cuff size according to the participant's arm circumference.

Measurements were performed in a dedicated room, with optimum temperature and lightning while respecting privacy.

Blood pressure values were categorised as follows:
a) Normal $-<120 \mathrm{mmHg}$
b) Pre-hypertension- $120-139 \mathrm{mmHg} / 80-89 \mathrm{mmHg}$
c) Mild Hypertension: $-140-159 \mathrm{mmHg} / 90-99 \mathrm{mmHg}$
d) Moderate hypertension: $160-170 \mathrm{mmHg} / 100 \mathrm{mmHg}$.
e) Severe hypertension: $>170 \mathrm{mmHg} / 100 \mathrm{mmHg}$

\section{RESULTS}

\section{Socio-Demographic Characteristics}

Table 1 illustrates that a total of 107 respondents participated in this research, of which $37.4 \%, 22.4 \%, 17.8 \%, 14.0 \%$ and $8.4 \%$ of

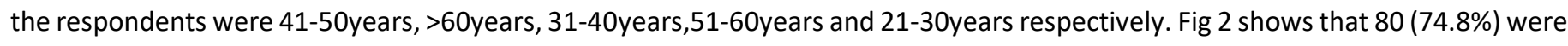
females and $27(25.2 \%)$ were males as shown in fig 2 . More than half $63(58.9 \%)$ of the females were married. Their age range of the respondents was between 21 and 80 years, but most 40 (37.4\%) were between 41 and 50 years. The mean age was 49.4 years and the standard deviation was 13.7 years. Forty-three $(40.2 \%)$ of the respondents had tertiary education while about $4.7 \%(5)$ had no formal education. Fig 3 illustrates that $50(46.7 \%)$ were self-employed, 19(17.8\%) were unemployed while 5(4.7\%) were civil servants. Sixty-seven (62.6\%) respondents earned less than N100, 000 as monthly incomes, which is considered low. The above results are also illustrated in figure 1.

Table 1: Socio-demographic Characteristics.

\begin{tabular}{lll}
\hline Age & Frequency $(\mathbf{n}=\mathbf{1 0 7})$ & Percent \\
$21-30$ years & 9 & \\
$31-40$ years & 19 & 8.4 \\
$41-50$ years & 40 & 17.8 \\
$51-60$ years & 15 & 37.4 \\
Over 60 years & 24 & 14.0 \\
Mean Age (SD) & $49.4(13.7)$ & 22.4 \\
Sex & & \\
Male & 27 & 25.2 \\
Female & 80 & 74.8 \\
Marital Status & & \\
Single & 20 & 18.7 \\
\hline
\end{tabular}




\begin{tabular}{lll}
\hline Married & 63 & 58.9 \\
Divorced & 1 & 0.9 \\
Separated & 3 & 2.8 \\
Widowed & 20 & 18.7 \\
Level of Education & & \\
Primary & 27 & 25.2 \\
Secondary & 32 & 29.9 \\
Tertiary & 43 & 40.2 \\
Non-formal & 5 & 4.7 \\
Occupation & & \\
Self-employed & 50 & 46.7 \\
Unemployed & 19 & 17.8 \\
Student & 7 & 6.5 \\
Others & 24 & 22.4 \\
Civil Servant & 5 & 4.7 \\
Retired & 2 & 1.9 \\
Monthly Income & & \\
Low & 67 & 62.6 \\
Medium & 20 & 18.7 \\
High & 20 & 18.7 \\
\hline
\end{tabular}

\section{SD=Standard deviation}

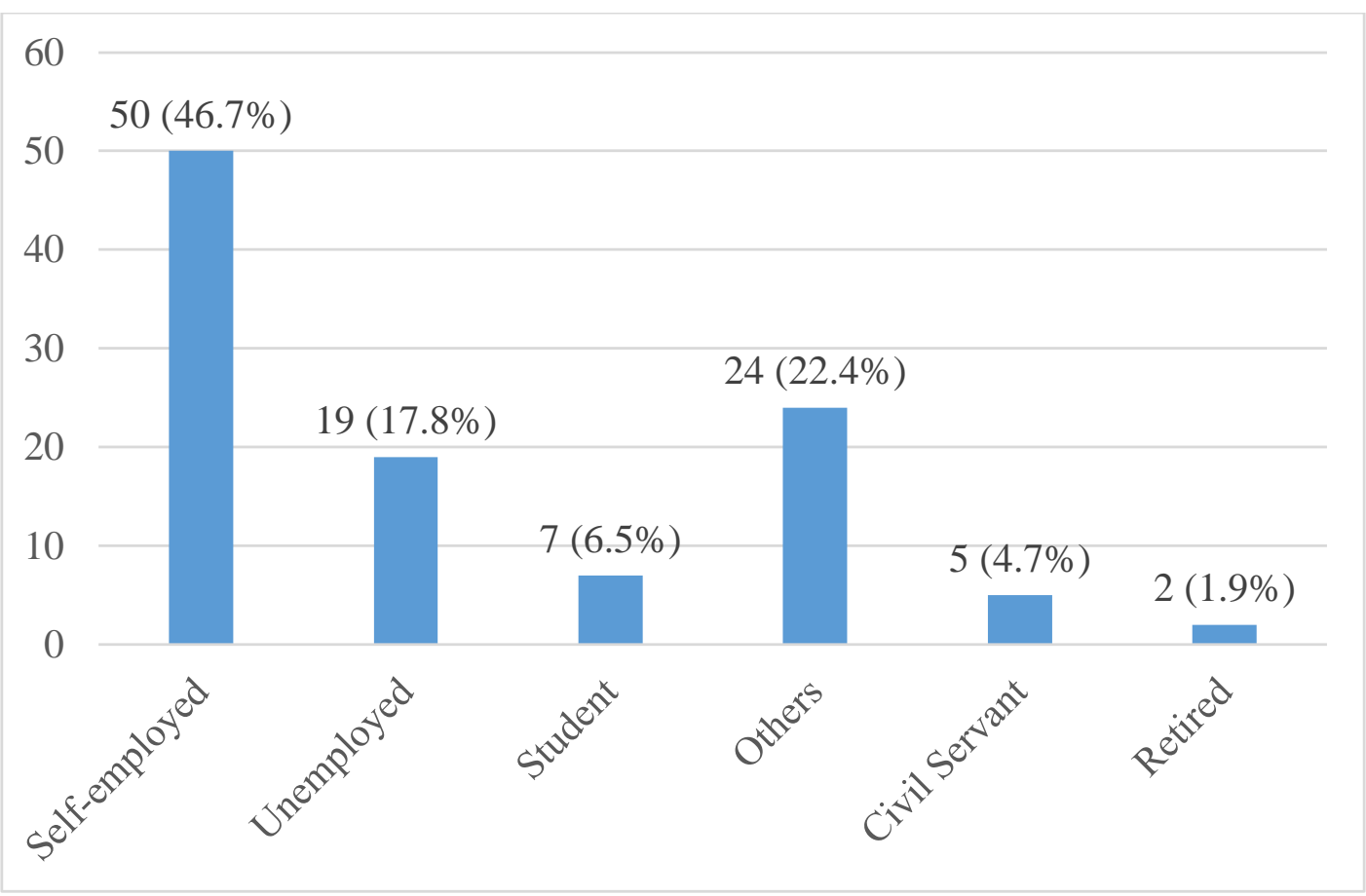

Fig 1 A bar chart showing distribution of occupation of respondents

\section{Life Style Characteristics/Medical History}

Only 11 (10.3\%) of the respondents smoke tobacco and were all previous smokers, 28 (26.2\%) currently drink alcohol, 84 (78.5) do not consume adequate amount of fruits and vegetables, 16 (15.0\%) add extra salt to their meal and 51 (47.7\%) do no engage in physical activities. Thirty-five (32.7\%) of the respondents reported history of hypertension while 43 (40.2\%) reported family history of hypertension, (table 2). Most of the participants never consumed alcohol (51.4\%) nor smoked (91.6\%) 
Knowledge, Attitudes and Practices of Hypertension amongst Apparently Healthy Adults in a Rural Setting in Rivers State

Table 2: Life style characteristics/medical history

\begin{tabular}{lll}
\hline & Frequency ( $\mathbf{n}=\mathbf{1 0 7})$ & Percent \\
\hline Tobacco Use & & \\
Never Smoked & 96 & 89.7 \\
Previous Smoker & 11 & 10.3 \\
Alcohol Consumption & & \\
Current Drinker & 28 & 26.2 \\
Previous Drinker & 31 & 29.0 \\
Never Drank & 48 & 44.9 \\
Fruit and Vegetable Consumption & & \\
Adequate & 23 & 21.5 \\
Inadequate & 84 & 78.5 \\
Salt Consumption & & \\
Add extra salt to meal & 16 & 15.0 \\
Do not add extra salt to meal & 91 & 85.0 \\
Engage in Physical Activity & & \\
Yes & 56 & 52.3 \\
No & 51 & 47.7 \\
History of Hypertension & & \\
Yes & 35 & 32.7 \\
No & 72 & 67.3 \\
Family History of Hypertension & & \\
Yes & 43 & 40.2 \\
No & 64 & 59.8
\end{tabular}

\section{Knowledge about Hypertension}

Seventy-nine (73.8\%) of the respondents defined hypertension as high blood pressure, 87 (81.3\%) were aware that hypertension was extremely dangerous to health, 15 (14.0\%) were aware that both systolic and diastolic blood pressure measurements were important in establishing hypertension status, 84 (78.5\%) were aware that things can be done to lower blood pressure level, and 89 (83.2\%) were aware that lowering blood pressure even a little can help improve health. Overall, 84 (78.5\%) of the respondents had good level of knowledge about hypertension (table 3).

Table 3: Knowledge about Hypertension

\begin{tabular}{lll}
\hline & \multicolumn{2}{c}{ Percent } \\
\hline Meaning of hypertension & Frequency $(\mathbf{n}=\mathbf{1 0 7})$ \\
High blood pressure & 79 & 73.8 \\
High level of stress/tension & 21 & 19.6 \\
High blood sugar & 1 & 0.9 \\
Over activity & 3 & 2.8 \\
No response & 3 & 2.8 \\
How dangerous hypertension is to health & & \\
Extremely dangerous & 87 & 81.3 \\
Somewhat dangerous & 12 & 11.2 \\
Not at all dangerous & 3 & 2.8 \\
Do not know & 5 & 4.7 \\
Most important measurement in hypertension & & 18.7 \\
Systolic blood pressure & 20 & \\
\hline
\end{tabular}


Knowledge, Attitudes and Practices of Hypertension amongst Apparently Healthy Adults in a Rural Setting in Rivers State

\begin{tabular}{lll}
\hline Diastolic blood pressure & 15 & 14.0 \\
Both & 15 & 14.0 \\
Do not know & 57 & 53.3 \\
People can do things to lower blood pressure & & \\
Yes & 84 & 78.5 \\
No & 1 & 0.9 \\
Do not know & 22 & 20.5 \\
Lowering blood pressure even a little bit improves health & & \\
Yes & 89 & 83.2 \\
No & 3 & 2.8 \\
Do not know & 15 & 14.0 \\
Overall knowledge about hypertension & & \\
Poor & 23 & 21.5 \\
Good & 84 & 78.5 \\
\hline
\end{tabular}

\section{Attitude towards Hypertension Prevention}

Most 63 (58.9\%) of the respondents strongly agreed that regular checking of blood pressure is important, most $43(40.2 \%)$ agreed that reduced salt intake help prevent hypertension, most $49(45.8 \%)$ agreed that keeping in touch with physician regularly help prevent hypertension, most $52(48.6 \%)$ agreed that regular medication is important in hypertension, while 45 (42.1\%) each strongly agreed and agreed to exercise regularly for healthy life. Overall, 97 (90.7\%) of respondents had positive attitude towards hypertension prevention (table 4).

Table 4: Attitude towards Hypertension Prevention

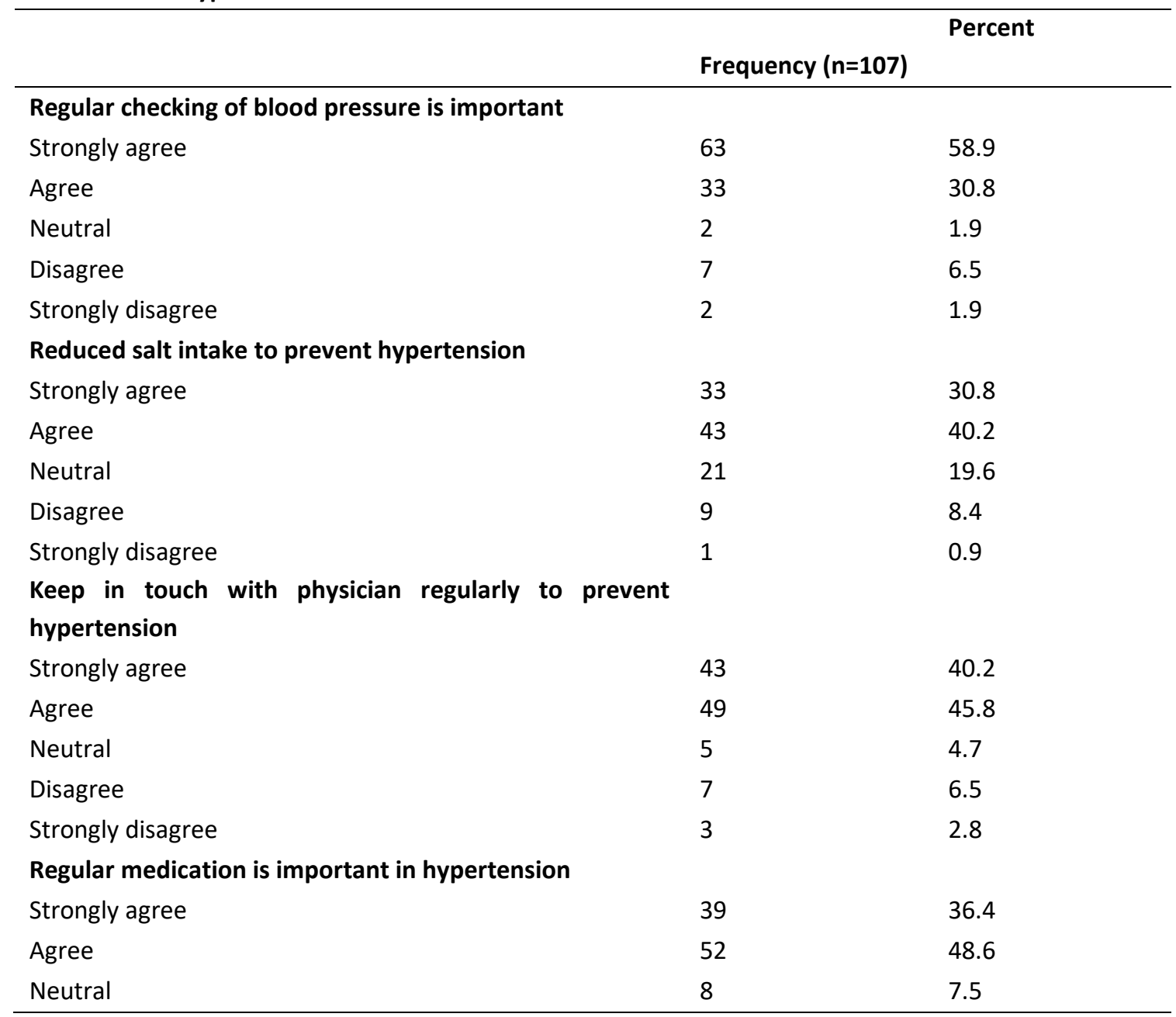


Knowledge, Attitudes and Practices of Hypertension amongst Apparently Healthy Adults in a Rural Setting in Rivers State

\begin{tabular}{lll}
\hline Disagree & 4 & 3.7 \\
Strongly disagree & 4 & 3.7 \\
Exercise regularly for health life & & \\
Strongly agree & 45 & 42.1 \\
Agree & 45 & 42.1 \\
Neutral & 10 & 9.3 \\
Disagree & 5 & 4.7 \\
Strongly disagree & 2 & 1.9 \\
& & \\
Positive & 97 & 90.7 \\
Negative & 10 & 9.3 \\
Overall mean (SD) & $1.86(0.67)$ & \\
\hline
\end{tabular}

$\mathrm{SD}=$ Standard deviation

\section{Practice of Hypertension Prevention}

Among the respondents interviewed, 27 (25.2\%) frequently check their blood pressure, 52 (48.6\%) frequently avoided consumption of salty food, 100 (93.8\%) never or occasionally consumed alcohol, 78 (72.9\%) never or occasionally performed physical activity, 8 (7.5\%) frequently checked their body weight, 98 (91.6) never smoked tobacco, and 16 (15.0\%) frequently consulted their health care provider. Only $32(29.9 \%)$ of the respondents had check their blood pressure status with the past 1 month (table 5).

Table 5: Practice of Hypertension Prevention

\begin{tabular}{|c|c|c|}
\hline & Frequency $(n=107)$ & Percent \\
\hline \multicolumn{3}{|c|}{ Measure blood pressure } \\
\hline Never & 14 & 13.1 \\
\hline Occasional & 66 & 61.7 \\
\hline Frequent & 27 & 25.2 \\
\hline \multicolumn{3}{|c|}{ Moderate salt intake } \\
\hline Never & 8 & 7.5 \\
\hline Occasional & 49 & 45.8 \\
\hline Frequent & 50 & 46.7 \\
\hline \multicolumn{3}{|c|}{ Avoid salty food consumption } \\
\hline Never & 19 & 17.8 \\
\hline Occasional & 36 & 33.6 \\
\hline Frequent & 52 & 48.6 \\
\hline \multicolumn{3}{|c|}{ Consume alcohol } \\
\hline Never & 55 & 51.4 \\
\hline Occasional & 45 & 42.1 \\
\hline Frequent & 7 & 6.5 \\
\hline \multicolumn{3}{|c|}{ Perform physical activity } \\
\hline Never & 14 & 13.1 \\
\hline Occasional & 64 & 59.8 \\
\hline Frequent & 29 & 27.1 \\
\hline \multicolumn{3}{|c|}{ Check body weight } \\
\hline Never & 29 & 27.1 \\
\hline Occasional & 70 & 65.4 \\
\hline Frequent & 8 & 7.5 \\
\hline Smoke & & \\
\hline
\end{tabular}



State

\begin{tabular}{lll}
\hline Never & 98 & 91.6 \\
Occasional & 6 & 5.6 \\
Frequent & 3 & 2.8 \\
$\begin{array}{l}\text { Consult health care provider } \\
\text { Never }\end{array}$ & 14 & 13.1 \\
Occasional & 77 & 72 \\
Frequent & 16 & 15 \\
When blood pressure was measured last & & \\
Less than 7 days & 15 & 14 \\
7 days to 1 month & 17 & 15.9 \\
Over 1 month to 1 year & 30 & 28 \\
Over 1 year or never & 45 & 42.1
\end{tabular}

In summary majority of the respondents had higher knowledge and positive attitude towards hypertension but low level of hypertension care related practice.

\section{DISSCUSSION}

This study reveals that $37.4 \%, 22.4 \%, 17.8 \%, 14.0 \%$ and $8.4 \%$ of the respondents were $41-50$ years, $>60$ years, 31-40years,51-60years and 21-30years respectively. $84(78.5 \%)$ of the study population had good knowledge on hypertension. As regards practice of hypertension prevention and control only $25.2 \%$ (27) frequently checked their blood pressure while $61.7 \%$ (66) occasionally checked. We had more respondents with positive attitude in this study (90.7\%). These findings were supported by a study conducted by Md Nahian ET $\mathrm{al}^{16}$ in Bangladesh on the knowledge, attitude and practice of hypertension. In their study the age range of 36-50years constituted most of the participants. Their study also showed that more than half of the respondents (53.36\%) had proper knowledge on hypertension, (85.68\%) had positive attitude towards hypertension. While $13.1 \%$ of respondents never checked their blood pressure in the index study, the study conducted by Nahian etal ${ }^{16}$, had about $63.8 \%$ of their respondents who never checked their blood pressure. Females were more in this study but compared to the study by Nahian etal ${ }^{16,}$ males were more, while Azubuike eta ${ }^{17}$ had only females as their participants. In contrast, the study by Azubuike etal ${ }^{17}$, more than half of the respondents (61.3\%) had good practice, while knowledge and attitude were poor. In this study, we had more self-employed people (46.7\%) but another study found dominant occupation was civil service (34.9\%)16 and another study showed housewives were more dominant $(37.5 \%)^{16}$. There were more married people (58.9\%) in the case study, this is also supported by (64.5\%)' while in the index study we had more people who checked their blood pressure occasionally (61.7\%), in the study by Nahan etal ${ }^{16}$, and they had more people who never checked (68.30\%).

Positive attitude is seen in the index study as regards the use of medication for the management of hypertension 52 (48.6\%). This is also similar to what has been reported in some previous studies amongst hypertensive patients ${ }^{16,18-21}$. In contrast to the aforementioned studies, Azubuike and $\mathrm{Kurmi}^{17}$ in their study showed that only 44 (17.5\%) of the respondents had strong positive attitude towards the use of medications in the management of hypertension. Concerning life style modification as it affects hypertension control, only less than half 45 (42.1\%) of respondents in the index study have a knowledge of exercise been helpful in the control of hypertension. This is not supported by another study which found out that patient's knowledge of exercise and as it affects hypertension were $59.2 \%$ and $67.7 \%$ respectively ${ }^{22}$. In the case study, the attitude towards exercise is poor when compared with the result of the research done in Ghana $(60 \%)^{23}$. The attitude of respondents towards tobacco and alcohol consumption is commendable as shown in this study, $96.1 \%$ never took tobacco while $51.4 \%$ never took alcohol. This fact is also supported in a study done in Bangladesh ${ }^{17}$, where $98.5 \%$ avoided cigarette smoking this research shows that $48.6 \%$ frequently avoid salty food consumption, while $46.7 \%$ frequently indulge in moderate salt consumption. On the contrary, a study conducted in Bangladesh shows that $94.6 \%$ avoided salt intake ${ }^{16}$. Weight reduction is also a lifestyle modification necessary for the control of hypertension, the attitude of respondents in the index case are as follows, $27.1 \%$ never checked their weight, $7.5 \%$ frequently checked while $65.4 \%$ occasionally checked.

45(42.1\%) of the respondents in the index study never checked their blood pressure while 17 (15.9\%) had their blood pressure checked within the last 7days to1month before they presented at the survey. A similar scenario was also observed in the study conducted by Nahan etal ${ }^{16}$, where more than half of respondents $(68.30 \%)$ never checked their blood pressure. 


\section{Knowledge, Attitudes and Practices of Hypertension amongst Apparently Healthy Adults in a Rural Setting in Rivers State}

In summary the index study shows that the respondents have good knowledge and attitude but poor practice towards hypertension prevention and control. Therefore, it is recommended that health care providers frequently educate patients at any given opportunity on the importance of life style modification, regular visit to a health care provider for blood pressure checks as well as regular intake of one's medication when diagnosed hypertensive if the prevention and control of hypertension and its complications are to be achieved.

During the course of data collection, we had some limitations such as inability to follow up participants with undiagnosed high blood pressure since the data was obtained from a random survey. There was also difficulty in taking repeated blood pressure measurements because participants were not willing to spend more of their time. Some participants were also unwilling to divulge some information which they considered personal. Language was also a challenge because some respondents could neither understand nor speak English.

\section{CONCLUSION}

The survey revealed lapses in knowledge, attitude and behavioural practices as regards hypertension.

Majority of respondents had higher knowledge and positive attitude towards hypertension but low level of practice.

Appropriate level of education is therefore necessary to improve this low level of practice of hypertension prevention and control amongst the populace

\section{REFERENCES}

1) He J, Whelton PK. Epidemiology and prevention of hypertension. Med Clin North Am. 1997; 81: 1077-1097.

2) Charles N, Shweta B. Hypertension: Hypertension crisis (Hypertension, hypertensive emergencies, hypertensive urgency, malignant hypertension). Renal and Urology News; 2018.

3) Mozaffurian D, Benjamin EJ, Go AS, et al. Heart disease and stroke statistics - 2015 update: a report from the American Heart Association Circulation. 2015; 131(4); e29-e322.

4) Ezzati M, Lopez AD, Rodgers A, et al. Selected major risk factors and global and regional burden of disease. Lancet. 2002; 360: 1347-1360.

5) World Health Organization. A global brief on hypertension: Silent killer, global public health crises: World Health Day 2013, 2013.

6) Monitoring Health for the SDGs. World Health Statistics: 2017, 116p.

7) Dore G, Nagpol T. Urbanization in Mongolia: pursuing sustainability in a unique environment. Environment: Science and Policy for Sustainable Development: 2006(6): 10-24.

8) Aubert L, Bovet $P$, Gervasoni JP, et al. Knowledge, attitudes and practices on hypertension in a country in epidemiological transition. Hypertension. 1998: 31(5): 1136-1145.

9) Harsch S. Health Literacy in crisis affected Afghanistan: a quantitative study on beliefs and barriers: Stefanie Harsch European Journal of Public Health. 2017; 27(suppl_3)

10) Malik A, Yoshida Y, Erkin T, et al. Hypertension -related knowledge, practice and drug adherence among inpatients of a hospital in Samarkand, Uzbokistan. Nagoya J Med Sci. 2014; 76 (3-4): 255 -263.

11) Dodu SRA. Emergence of cardiovascular disease in developing countries. Cardiology 1998; 75: 5664.

12) Whelton PK, He J, Appel LI, Cutler JA, Hawas S, Kotchen TA. Primary prevention of hypertension: Clinical and public health advisory from the National high blood pressure Education program. JAMA.2012; 288: 1882-1888.

13) Ifeoma IU, Chinwuba KI, Bosden JCO, Arodiwe E, Onodugo E, Okafor C. High prevalence and low awareness of hypertension in a market population in Enugu, Nigeria.Int.J hypertension: 2011; 86967510.

14) Obinna IE, Patrick OU, Izuchukwu LN. Prevalence, awareness, treatment and control of hypertension in a Nigerian population. Health 2010; 2:731-735.

15) Kofi Janet, Keski-Pohjanmaan ammatt, Korkealoulu. 2012. Prevenyion and management of hypertension. A study on knowledge and attitudes of women of child bearing age.

16) Nahian Rahman MD, et al. Knowledge, attitude and practice about hypertension among adult people of selected areas of Bangladesh

17) 17. Azubuike SO, Kurmi R. Awareness, practice and prevalence of hypertension among rural Nigerian women. Arch Med Health Sci.2014; 2 :23-28. 
18) 18. Addo J, Amoah AG, Koram KA. The changing patterns of hypertension. A study of four rural communities in the GA district. Ethn Dis. 2006; 16: 894-899.

19) 19.Demaio AR, Otgontuya $D$, De Courten $M$, et al. Hypertension and hypertension related disease in Mongolia; findings of a national knowledge, attitude and practices. Study. BMC Public Health. 2013; 13: 194.

20) 20. Kusuma YS, Gupta SK, Pandav CS. Knowledge and perceptions about hypertension among settled migrants in Delhi, India. CVD Prev Control. 2009; 14:119-129.

21) 21.Oliveria SA, Chen RS, McCarthy BD, et al. Hypertension knowledge, awareness and attitudes in a hypertensive population. Gen Interm Med. 2005; 20: 2019-2025.

22) 22.Tesema S, Disasa B, Kebamo S. Knowledge, Attitude and Practice Regarding Lifestyle Modification of Hypertensive patients at Jimma University Specialized Hospital, Ethiopia. Primary Health Care. 2016; 6: 218.

23) 23. Marfo AF, Owusu- Daaku FT, Addo MO, et al. Ghanaian hypertensive patients understanding of their medicines and lifestyle modification for managing hypertension. Int J Pharm Sci. 2014; 6: 165-170. 